\title{
What Can Machine Learning Tell Us About Intraday Price Patterns in a Frontier Stock Market?
}

\author{
Dan Gabriel Anghel ${ }^{1}$ \\ ${ }^{1}$ Department of Money and Banking, The Bucharest University of Economic Studies, Romania \\ Correspondence: Dan Gabriel Anghel, Department of Money and Banking, The Bucharest University of Economic \\ Studies, Romania. Tel: 40-723-155-148. E-mail: dan.anghel@ fin.ase.ro
}

Received: June 15, 2020

Accepted: July 30, 2020

Online Published: October 4, 2020

doi:10.5430/ijfr.v11n5p205

URL: https://doi.org/10.5430/ijfr.v11n5p205

\begin{abstract}
Quite a lot. On the one hand, it enables us to classify intraday patterns into 6 unique classes and to show how each class is related to several important market state variables. On the other hand, it enables us to identify the relevant set of variables and define a better model of the drivers of intraday patterns in a frontier stock market. Overall, our results show that intraday patterns in returns in the frontier stock market of Romania are mostly the result of risk, information flows, and spillover effects from more developed international markets. However, we find that low market efficiency and investor behavior also have a significant contribution. Among others, we identify signs of overreaction to information, irrational exuberance and "making the close" practices by different types of investors.
\end{abstract}

Keywords: intraday patterns, stock returns, machine learning, clustering, frontier stock market

\section{Introduction}

Intraday patterns in stock returns have been documented more than three decades ago by Wood, McInish, and Ord (1985) for the US market and have since been observed in all types of markets, from developed (e.g. Andersen, Bollerslev, and Cai, 2000, investigate the Japanese market) to emerging (e.g., Bildik, 2001, discusses the case of the Turkish market) and frontier (e.g., Tissaoui, 2012, analyzes the Tunisian market). The search for economic justifications has since been intense, with various factors being used to explain the occurrence of the observed patterns. Evidently, patterns can arise due to market architecture and characteristics, such as the limited trading program, mid-day breaks, or auction-based trading mechanisms. The flow of information in the form of macroeconomic or corporate news announcements, overnight accumulation of information, and spillover effects caused by asymmetric information should also be important. Liquidity and inventory risk should further play an important role in explaining intraday patterns in returns (Amihud and Mendelson, 1987). Moreover, microstructural frictions such as trade clustering around the opening and closing times should also be important, an idea going back to Admati and Pfleiderer (1989). This is related to investor trading patterns (Yadav and Pope, 1992). On the one hand, Gao, Han, Li, and Zhou (2018) recently document an intraday momentum effect that can be explained by investors infrequently rebalancing their portfolios and late-informed trading near the market close. Renault (2017) directly links this effect to investor sentiment that can be measured via social media platforms on which investors are active. On the other hand, Block, French, and Maberly (2000) document that institutional investors are mainly active during early and late trading hours and display relatively higher proportions of buy decisions, this partially explaining some of the observed patterns in liquidity, volatility, and returns. Similarly, institutional investors have been found to engage in "window dressing", "making the close" practices toward the end of financial reporting periods, this being a form of market price manipulation (Putniņš, 2012). Finally, various forms of price manipulation have also been linked with intraday patterns, especially near market closing times (Comerton-Forde and Putniņš, 2011).

Intraday patterns in returns are not unique to stock markets. For example, Breedon and Ranaldo (2013) show that foreign exchange markets also exhibit them, mainly related to the open-close times of international financial centers, market microstructure (order flow) and the behavior of market participants, such as their tendency to be net sellers of the domestic currency during their own trading hours. Zhang (2018) additionally finds that domestic currencies tend to appreciate during U.S. trading sessions. Likewise, intraday patterns can be observed in other stock market variables, such as liquidity (e.g., Ahn and Cheung, 1999), volatility (e.g., Andersen et al., 2000), or trading costs, 
bid-ask spreads (e.g., Vo, 2007). However, compared to patterns in volatility and liquidity, the drivers of intraday patterns in returns are not so straight-forward to explain as they possibly conflict with the important theoretical concept of market efficiency (Fama, 1970). Although many studies try to provide explanations, there are overwhelmingly concentrated on developed stock markets, especially the one in the US. Among others, the existing literature has yet to offer thorough explanations regarding the heterogeneity of intraday patterns across different markets or their time-varying nature in the same market. The low accessibility of intraday data is one of the major hurdles for the advancement of knowledge on this topic. Consequently, intraday patterns in stock returns are still poorly understood, especially in small, developing markets.

This paper adds to the literature by investigating intraday patterns in returns in the frontier stock market of Romania. The analysis focuses on this market because it presents some unique characteristics that that could potentially influence intraday patterns. For example, the opening and closing times have underwent multiple changes throughout its recent history (as shown in Figure 1), which makes this market an ideal natural experiment for investigating if the trading program is one of the factors that drives the shape of intraday patterns. Also, being a small, less liquid and less efficient market (Anghel, 2017) could lead to a different behavior compared to more developed counterparts but very few papers can be found in the literature that analyze this topic. Our choice of market is also based on the availability of a lengthy data sample, consisting of tick-by-tick transaction data from 2005 to 2020, which makes it possible to investigate pattern behavior over an extensive period of time.

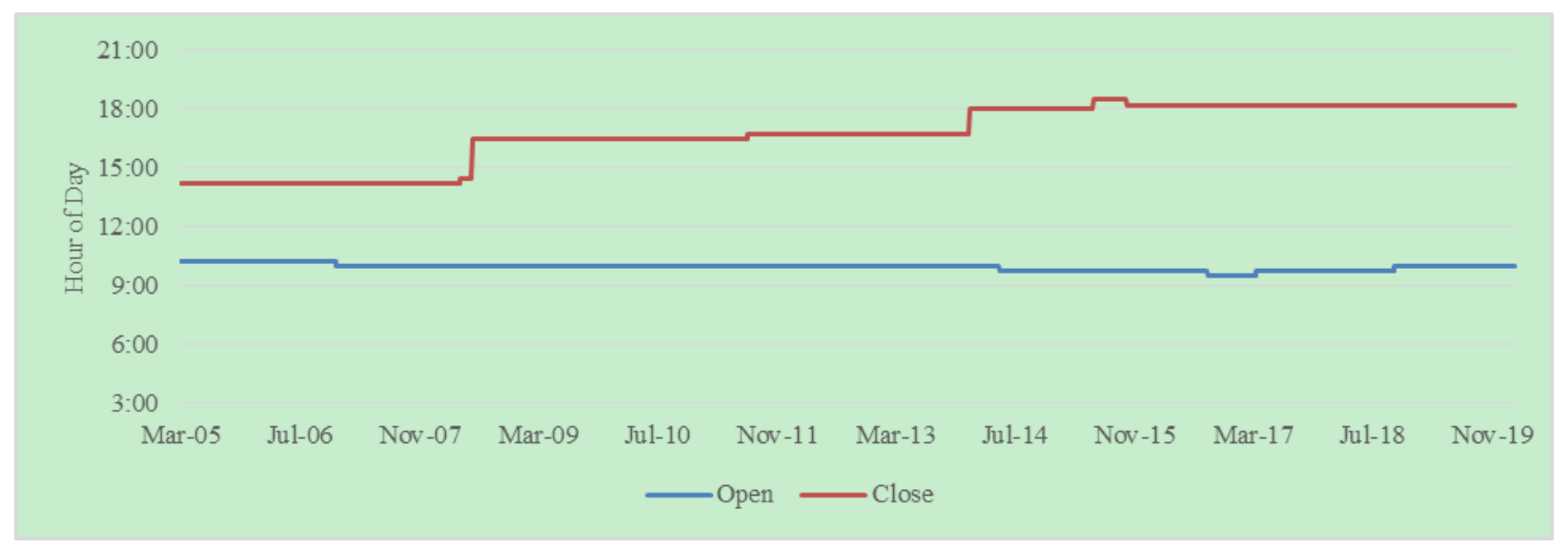

Figure 1. Opening and closing times on the Romanian stock market

Our contribution is thus twofold. First, we investigate the drivers of intraday patterns in a small, frontier stock market. This is not the first time when this topic is analyzed in the Romanian market (Anghel, Țilică, and Dragotă, 2020, have recently shown that patterns exist) or, more generally, in a frontier market. However, to the extent of our knowledge, it is the first time when quantitative models are used to explain their dynamic, and not just to observe the general characteristics. Second, we offer a classification of the different types of patterns that can occur in the market and describe the context in which they appear, using clustering methods derived from Machine Learning algorithms. On the one hand, this enables us to estimate the prevalence of the different types of patterns and their relative contribution in the formation of the overall pattern. On the other hand, it provides a better overview of the variables that are more strongly associated with the patterns, which in the end enables us to define and estimate a model that better highlights the drivers of (and their individual influence on) the observed intraday patterns.

The remaining of the paper is organized as follows. Section 2 presents the data sample and provides an overview of the general intraday pattern in returns observed on the Romanian stock market. Section 3 investigates the possible classes of intraday patterns based on a clustering model that is "trained" via Machine Learning techniques. Section 4 uses this result to define and estimate a linear model of the drivers of intraday patterns. Section 5 concludes.

\section{Data and Overview of Intraday Patterns}

We use series of 1-minute log-returns for all stocks listed in the Romanian market (at the Bucharest Stock Exchange, https://www.bvb.ro/) estimated from tick-by-tick trading data, which is collected from Tradeville (www.tradeville.eu) for the period March 7, 2005-December 11, 2015 and from Bloomberg for the period June 15, 2016-February 7, 
2020 (Note 1). We avoid survivorship bias by keeping companies that have been delisted before 2020 . However, we try to improve the reliability of results and avoid spurious effects by filtering out stocks with insufficient liquidity using the following criteria: (1) have traded for less than 3 years and are not currently listed; (2) have less than 3000 return observations for the entire sample period. This adjustments leads to a sample of $8,797,727$ trades and 5,281,563 1-minute returns for 159 individual stocks. A summary of the filtered data sample is provided in online Appendix A.

We use the individual return series for all stocks to compute a new series of equal-weighted market returns for all minutes in the sample (Note 2). Then, following Anghel et al. (2020), we split all trading days into two equal parts and label each minute according to the minimum absolute time difference relative to the market open or close. For example, the first minute of the trading day is labeled as $\mathrm{O}+1$, the second is $\mathrm{O}+2$, and so on. Similarly, the last minute of the day is labeled as $\mathrm{C}-0$, the one prior to that is $\mathrm{C}-1$, and so on. Note that we separately consider overnight returns because they differ from intraday returns, being impacted by the overnight accumulation of information and artificial price adjustments due to corporate events (e.g., dividends payments, splits, reverse splits). We thus compute them separately; more precisely, the return for a 1-minute intraday interval $i$ of day $t$ is calculated as $R_{t, i}=\ln \left(C_{t ; i} / C_{t i j-1}\right)$, except for $\mathrm{O}+1$ where the formula is $R_{t, 0+1}=\ln \left(C_{t ; 0+1} / O_{t, 0+1}\right)$, where $\mathrm{O}$ and $\mathrm{C}$ represent the open and close prices in the interval, respectively; the overnight return is $R_{t_{i} O N}=\ln \left(O_{t_{i} O+1} / C_{t-1 / C-0}\right)$.

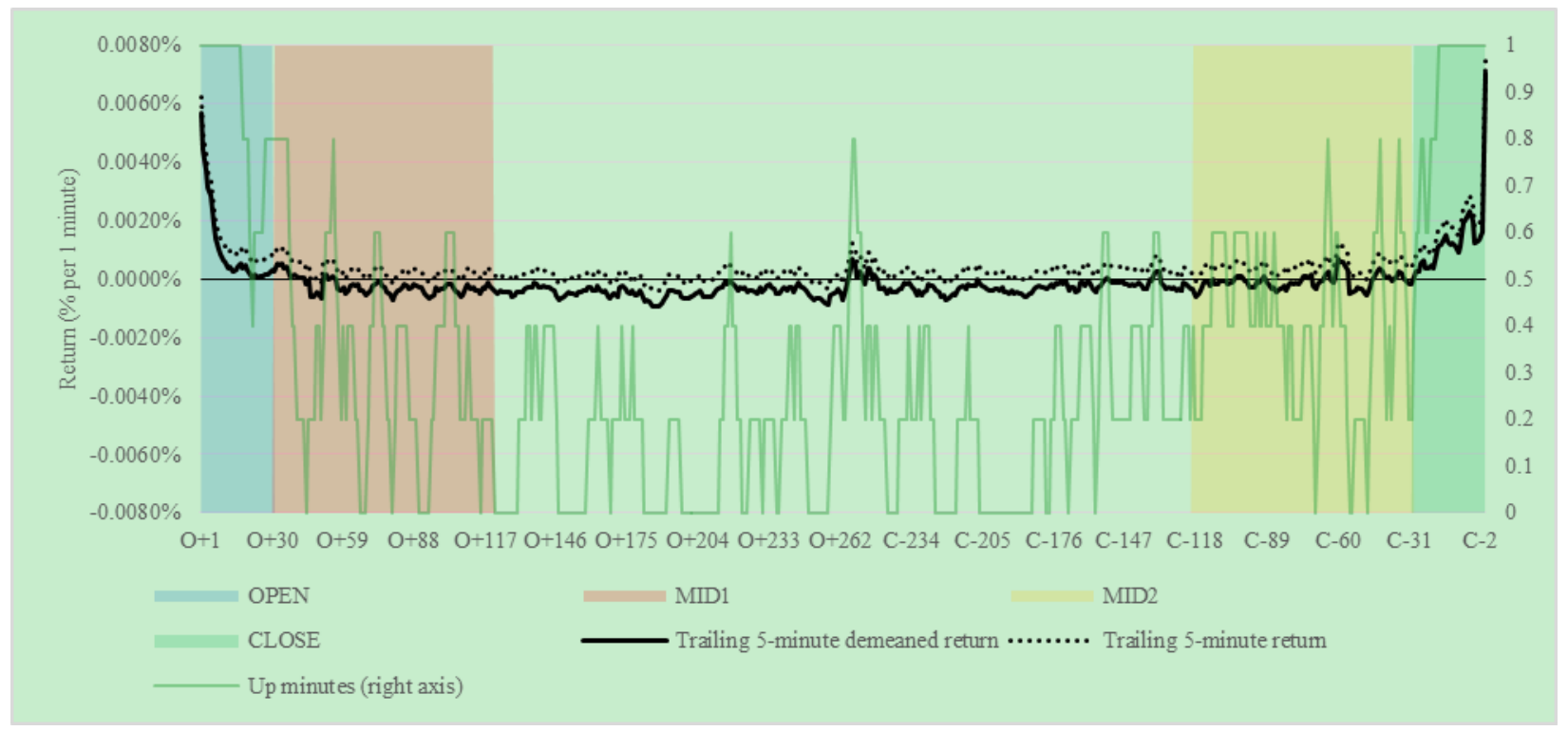

Figure 2. Average intraday pattern in stock returns on the Romanian market

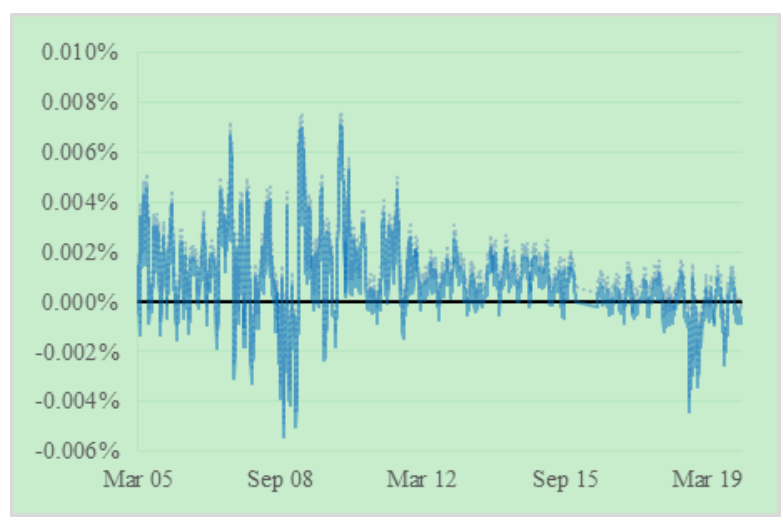

Panel A. OPEN effect

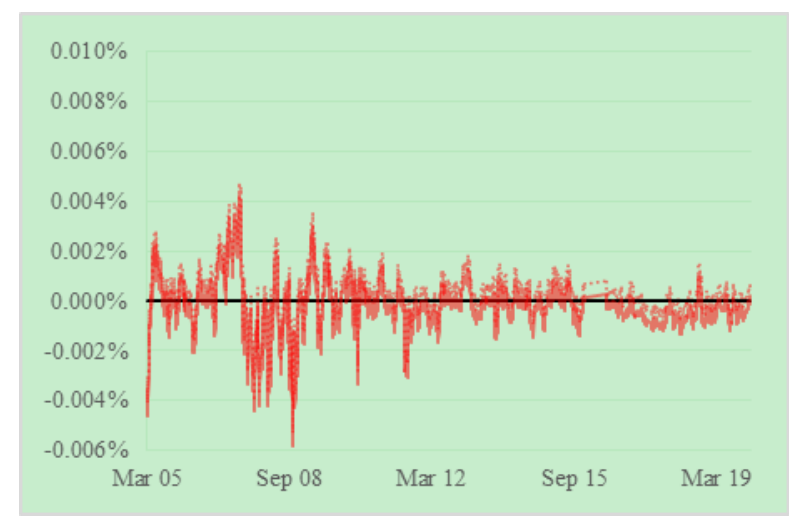

Panel B. MIDI effect 


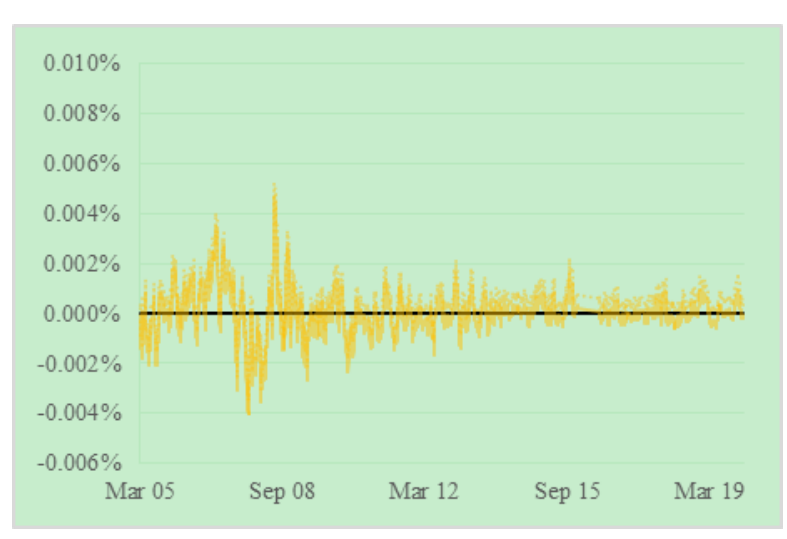

Panel C. MID2 effect

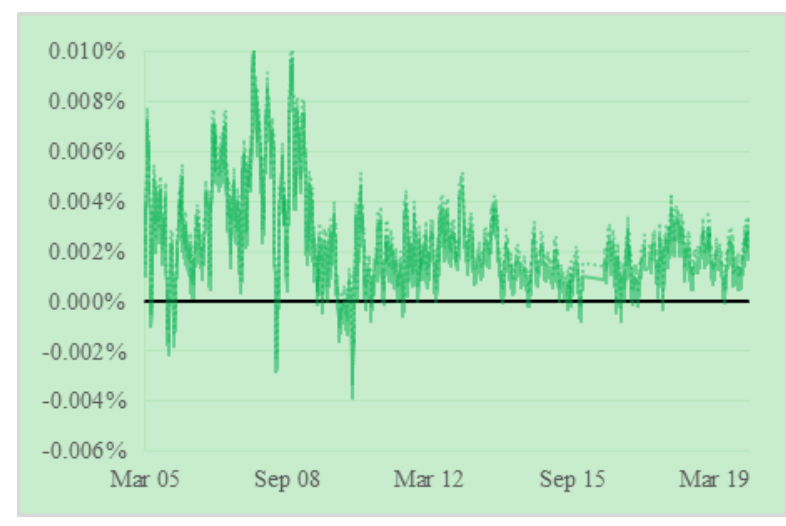

Panel D. CLOSE effect

Figure 2. Time variation of intraday effects

Averaging the returns on each interval over all days in the sample yields a general pattern in intraday returns. To visualize this, Figure 2 displays the 5-minute rolling average-using both raw returns and demeaned returns, which are obtained by subtracting the full sample average return. Also, we plot the ratio of the total number of positive returns over the total number of returns in the 5-minute window, denoted as "Up minutes". The results show a $\omega$-shaped intraday pattern, this resembling the findings of Anghel et al. (2020) and extending them to an updated sample that spans until 2020. In particular, one can identify four distinct intraday effects: (1) the OPEN effect designates the period of significant positive returns occurring in the first 30 minutes of the trading day, (2) the MIDI effect designates the period of significant negative returns occurring in the next 90 minutes after OPEN (Note 3); (3) the MID2 effect designates the period of significant negative returns occurring in the 90 minutes prior to CLOSE; and (4) the CLOSE effect designates the period of significant positive returns occurring in the last 30 minutes of trading (Note 4).

To visualize the dynamic of intraday effects, each day we compute the average return associated with each effect, $\quad R_{t, E F F}=\sum_{\mathrm{i} \in E F F} R_{\mathrm{t}, \mathrm{i}} /|E F F| \quad$ where $\quad$ EFF is either $O P E N=\{O+1, \ldots+30\}$, $M I D 1=\{O+31, \ldots, O+120\}, M I D 2=\{C-119, \ldots, C-30\}$, or CLOSE $=\{C-29, \ldots, C-0\}$; and plot the 21-day rolling average in Figure 3. Anghel et al. (2020) highlighted that intraday patterns change in time, and we also observe this in our extended sample. We hereafter investigate the reasons behind this dynamic; first, we are interested to test if same-day effects are independent or not, i.e. if distinguishable classes of relevant intraday patterns exist. This analysis is performed in Section 3.

\section{Classes of Intraday Patterns in Stock Returns}

We investigate what factors are associated with the observed dynamic by first classifying the types of patterns that can be observed. We do this by employing a clustering model that is trained via Machine Learning (ML) algorithms. Specifically, we use a Bayesian Gaussian Mixture Model (see, e.g., Marin, Mengersen, and Robert, 2005, for a detailed discussion on this type of models). The fitting algorithm starts with priors initialized using the K-means clustering method and then successively evaluates and updates the model coefficients (the probabilities associated with each observation being part of a cluster) according to Bayes' theorem. We assume no more than 20 types (clusters) of intraday patterns and keep the best performing model resulting from 1000 initializations, which are used similar to bootstrap resamples in order to minimize the bias associated with a suboptimal convergence of the ML algorithm. The actual implementation, listed below, is based on the BayesianGaussianMixture class that is part of the scikit-learn library in Python (Note 5):

BayesianGaussianMixture(covariance_prior=None, covariance_type $=$ 'full', degrees_of_freedom_prior=None, init_params $=$ 'kmeans', max_iter $=1000$, mean_precision_prior $=N o n e$, mean_prior=None, $n \_c o m p o n e n t s=20, n \_i n i t=1000$, random_state $=$ None, reg_covar $=1 e-06$, tol $=0.001$, verbose $=0, \quad$ verbose_interval $=10, \quad$ warm_start $=$ False, weight_concentration_prior $=$ None, weight_concentration_prior_type='dirichlet_process') 
The number of dimensions considered in the model is equal to the number of variables that we define as potentially drivers of intraday patterns. Specifically, we consider (1) factors associated with intraday liquidity and volatility (as well as higher order moments of the return distribution) in the domestic stock market; (2) factors associated with macroeconomic risk and the overall state of the economy; (3) factors associated with international information flows and possible spillover effects in returns or volatility from the US and European markets; (4) information related to calendar dates and the length of the trading day. Table 1 provides a summary and a detailed description of all variables, which are estimated on a daily basis. Note that all are standardized prior to introducing them in the clustering model in order to eliminate the known bias of ML algorithms that is related to variable scaling.

Table 1. List of variables, possible drivers of intraday patterns

\begin{tabular}{|c|c|c|}
\hline Type & Variable & Description \\
\hline \multirow{4}{*}{$\begin{array}{l}\text { Intraday effects in } \\
\text { stock returns }\end{array}$} & OPEN & OPEN effect: average 1-minute return from $\mathrm{O}+1$ to $\mathrm{O}+30$. \\
\hline & MID1 & MID1 effect: average 1-minute return from $O+31$ to $O+120$. \\
\hline & MID2 & MID2 effect: average 1-minute return from C-119 to C-30. \\
\hline & CLOSE & CLOSE effect: average 1-minute return from C-29 to C-0. \\
\hline Overnight return & ON & $\begin{array}{l}\text { Average overnight return, ONRET }=\frac{1}{m} \sum_{i=1}^{m} \ln \left(O_{i q i} / C_{i f-1}\right) \text {, where } m \text { is the total number of } \\
\text { stocks listed on day } t \text { and } \mathrm{O}, \mathrm{C} \text { are the opening and closing prices, respectively. }\end{array}$ \\
\hline \multirow{4}{*}{$\begin{array}{l}\text { Auto-dependence: } \\
\text { effects in the past }\end{array}$} & OPEN_PREVIOUS & OPEN effect in the previous trading day. \\
\hline & MID1_PREVIOUS & MID1 effect in the previous trading day. \\
\hline & MID2_PREVIOUS & MID2 effect in the previous trading day. \\
\hline & CLOSE_PREVIOUS & CLOSE effect in the previous trading day. \\
\hline \multirow{4}{*}{$\begin{array}{l}\text { Liquidity: trading } \\
\text { frequency }\end{array}$} & OPEN_NOTRADES & Average number of trades for each 1-minute interval during OPEN. \\
\hline & MID1_NOTRADES & Average number of trades for each 1-minute interval during MID1. \\
\hline & MID2_NOTRADES & Average number of trades for each 1-minute interval during MID2. \\
\hline & CLOSE_NOTRADES & Average number of trades for each 1-minute interval during CLOSE. \\
\hline \multirow{4}{*}{$\begin{array}{l}\text { Liquidity: value } \\
\text { of traded stocks }\end{array}$} & OPEN_TURNOVER & Total turnover during OPEN (sum of quantities traded times trading prices; mln. local currency). \\
\hline & MID1_TURNOVER & Total turnover MID1 (sum of quantities traded times trading prices; mln. local currency). \\
\hline & MID2_TURNOVER & Total turnover MID2 (sum of quantities traded times trading prices; mln. local currency). \\
\hline & CLOSE_TURNOVER & Total turnover CLOSE (sum of quantities traded times trading prices; mln. local currency). \\
\hline \multirow{4}{*}{$\begin{array}{l}\text { Volatility } \\
\text { estimated from } \\
\text { trading ranges }\end{array}$} & OPEN_ATR & $\begin{array}{l}\text { Average trading range, } A T R_{\mathrm{k}}=\frac{1}{m} \sum_{\mathrm{i=1}}^{\mathrm{m}} \ln \left(H_{\mathrm{i}, \mathrm{f}} / L_{\mathrm{i}, \mathrm{F}}\right) \text {, for the OPEN period, where } m \text { is the total } \\
\text { number of stocks listed on day } t \text {, while } \mathrm{H} \text { and } \mathrm{L} \text { are the high and low prices, respectively. }\end{array}$ \\
\hline & MID1_ATR & Average trading range for the MID1 period. \\
\hline & MID2_ATR & Average trading range for the MID2 period. \\
\hline & CLOSE_ATR & Average trading range for the CLOSE period. \\
\hline \multirow{4}{*}{$\begin{array}{l}\text { Cross-sectional } \\
\text { dispersion of } \\
\text { returns }\end{array}$} & OPEN_CSSD & $\begin{array}{l}\text { Cross-sectional standard deviation of returns, } \operatorname{CSS} D_{t}=\frac{1}{m} \sum_{i=1}^{m}\left(r_{4:}-\vec{r}\right)^{2} \text {, for the OPEN period, } \\
\text { where } m \text { is the total number of stocks listed on day } t \text {, while } \overline{\mathrm{r}} \text { is the average cross-sectional return. }\end{array}$ \\
\hline & MID1_CSSD & Cross-sectional standard deviation of returns for the MID1 period. \\
\hline & MID2_CSSD & Cross-sectional standard deviation of returns for the MID2 period. \\
\hline & CLOSE_CSSD & Cross-sectional standard deviation of returns for the CLOSE period. \\
\hline \multirow{3}{*}{$\begin{array}{l}\text { Time-series } \\
\text { volatility and } \\
\text { higher order } \\
\text { moments }\end{array}$} & VOL & 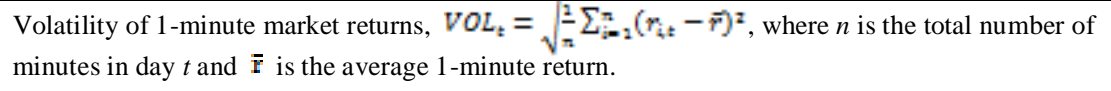 \\
\hline & SKEW & Skewness of 1-minute market returns. \\
\hline & KURT & Kurtosis (excess) of 1-minute market returns. \\
\hline \multirow[t]{2}{*}{$\begin{array}{l}\text { Macro } \\
\text { information }\end{array}$} & INTEREST & $\begin{array}{l}\text { Bid-Ask midpoint of end-of-day quotes for the } 12 \text {-month interest rate on interbank loans. Source: } \\
\text { National Bank of Romania. }\end{array}$ \\
\hline & EURRON & Log-return of the EUR/RON exchange rate. Source: National Bank of Romania. \\
\hline
\end{tabular}


USDRON Log-return of the USD/RON exchange rate. Source: National Bank of Romania.

EU Dummy variable taking 1 after January 1, 2007, and 0 otherwise. This is related to Romania being part of the European Union starting in 2007.

\begin{tabular}{|c|c|c|}
\hline \multirow{5}{*}{$\begin{array}{l}\text { Possible spillover } \\
\text { effects from more } \\
\text { developed } \\
\text { international } \\
\text { markets }\end{array}$} & SPX_RET_1 & $\begin{array}{l}\text { Log-return, } R E T_{\mathrm{E}}=\ln \left(C_{\mathrm{E}} / C_{\mathrm{t}-1}\right) \text {, of the Standard \& Poors } 500 \text { Index }(\mathrm{SPX}) \text { on the previous } \\
\text { trading day. Note that the previous day is considered because of the time-zone difference in order } \\
\text { to avoid look-ahead bias. Source of SPX series: Bloomberg. }\end{array}$ \\
\hline & SPX_TR_1 & Trading range of the Standard \& Poors 500 Index (SPX) on the previous trading day. \\
\hline & DAX_ONRET & $\begin{array}{l}\text { Overnight return, } \operatorname{ONRET}_{\mathrm{E}}=\ln \left(O_{\mathrm{t}} / C_{\mathrm{t}-1}\right) \text {, of the Deutscher Aktienindex }(\mathrm{DAX}) \text {, where } \mathrm{O} \text { and } \mathrm{C} \\
\text { are the opening and closing prices, respectively. Source of DAX series: Bloomberg. }\end{array}$ \\
\hline & DAX_INRET & Intraday return, $N N R E T_{k}=\ln \left(C_{t} / O_{t}\right)$, of the Deutscher Aktienindex (DAX). \\
\hline & DAX_TR & Trading range of the Deutscher Aktienindex (DAX). \\
\hline \multirow[t]{11}{*}{ Calendar effects } & MOY & Month of the year. \\
\hline & EOQ & Dummy variable taking 1 in months $3,6,9$, and 12 , and 0 otherwise. \\
\hline & BOQ & Dummy variable taking 1 in months $1,4,7$, and 10 , and 0 otherwise. \\
\hline & DOM & Day of the month. \\
\hline & EOMx, $x=1 . .5$ & Dummy variable taking 1 on day $T-x+1$, where $\mathrm{T}$ is the last day in a month (end of the month). \\
\hline & BOMx, $\mathrm{x}=1 . .5$ & $\begin{array}{l}\text { Dummy variable taking } 1 \text { on day } T+x-1 \text {, where } \mathrm{T} \text { is the first day in a month (beginning of the } \\
\text { month). }\end{array}$ \\
\hline & Monday & Dummy variable taking 1 for Monday and 0 otherwise. \\
\hline & Tuesday & Dummy variable taking 1 for Tuesday and 0 otherwise. \\
\hline & Wednesday & Dummy variable taking 1 for Wednesday and 0 otherwise. \\
\hline & Thursday & Dummy variable taking 1 for Thursday and 0 otherwise. \\
\hline & Friday & Dummy variable taking 1 for Friday and 0 otherwise. \\
\hline \multirow[t]{2}{*}{$\begin{array}{l}\text { Other market } \\
\text { information }\end{array}$} & DAYLENGTH & $\begin{array}{l}\text { Length of trading day, measured as the difference between close and open times, expressed in } \\
\text { minutes. }\end{array}$ \\
\hline & NOSTOCKS & Number of stocks (in our filtered sample) trading/listed in the market. \\
\hline
\end{tabular}

The algorithm that estimates the Bayesian Gaussian Mixture Model converges after 21 steps and shows that several types of intraday patterns exist. Table 2 presents a summary and a description of each, while detailed results are presented in the online Appendix B. Even though 20 different clusters are generated by the algorithm (this is the maximum number allowed), only 19 have sufficient observations (members). Moreover, a careful inspection of the similarities and differences between them shows that only 6 main types exist. These are redefined in the last column of the table.

We find that the most frequent pattern, which we denote as TYPICAL, can be formed by grouping 11 different clusters and occurs $85.04 \%$ of the time. Even though some cross-sectional differences exist between the average feature values of the component clusters (e.g., liquidity and volatility on near-BOM and near-EOM days are lower), the averages generally remain close to the mean, the differences are small, and, most importantly, the overall shape of the pattern is very similar, as shown in Panel A of Figure 3. This shows that it is probably the same type of pattern. The resulting re-labeling and re-estimation of the TYPICAL cluster can be visualized in Panel B of Figure 3.

Table 2. Clusters of intraday patterns

\begin{tabular}{lllrrrrl}
\hline No. & Days & Weight & $\begin{array}{r}\text { Average } \\
\text { OPEN }\end{array}$ & $\begin{array}{r}\text { Average } \\
\text { MID1 }\end{array}$ & $\begin{array}{r}\text { Average } \\
\text { MID2 }\end{array}$ & $\begin{array}{r}\text { Average } \\
\text { CLOSE }\end{array}$ & $\begin{array}{l}\text { Description, comments } \\
\text { No. }\end{array}$ \\
\hline 10 & 951 & $26.54 \%$ & $0.001186 \%$ & $0.000198 \%$ & $0.000456 \%$ & $0.001868 \%$ & TYPICAL pattern, with minor variations. \\
\hline 18 & 467 & $13.03 \%$ & $0.001818 \%$ & $0.000219 \%$ & $0.000233 \%$ & $0.003372 \%$ & TYPICAL pattern, with minor variations. \\
\hline 6 & 325 & $9.07 \%$ & $0.000948 \%$ & $0.000145 \%$ & $0.000359 \%$ & $0.001955 \%$ & Days near EOM but very similar to TYPICAL. \\
\hline 13 & 316 & $8.82 \%$ & $0.001708 \%$ & $0.000442 \%$ & $0.000385 \%$ & $0.002712 \%$ & TYPICAL pattern, with minor variations. \\
\hline
\end{tabular}




\begin{tabular}{|c|c|c|c|c|c|c|c|c|}
\hline 0 & 155 & $4.33 \%$ & $0.000765 \%$ & $0.000259 \%$ & $-0.000013 \%$ & $0.002550 \%$ & Days near EOM but very similar to TYPICAL. & 1 \\
\hline 9 & 149 & $4.16 \%$ & $0.001641 \%$ & $0.000659 \%$ & $0.000370 \%$ & $0.002001 \%$ & Days near BOM but very similar to TYPICAL. & 1 \\
\hline 19 & 146 & $4.07 \%$ & $0.001022 \%$ & $0.000425 \%$ & $0.000491 \%$ & $0.002132 \%$ & Days near BOM but very similar to TYPICAL. & 1 \\
\hline 16 & 145 & $4.05 \%$ & $0.001233 \%$ & $0.000154 \%$ & $-0.000023 \%$ & $0.002468 \%$ & Days near BOM but very similar to TYPICAL. & 1 \\
\hline 2 & 141 & $3.94 \%$ & $0.001386 \%$ & $-0.000042 \%$ & $0.000497 \%$ & $0.001668 \%$ & Days near EOM but very similar to TYPICAL. & 1 \\
\hline 7 & 140 & $3.91 \%$ & $0.001567 \%$ & $0.000533 \%$ & $0.000633 \%$ & $0.001996 \%$ & Days near BOM but very similar to TYPICAL. & 1 \\
\hline 1 & 137 & $3.82 \%$ & $0.001318 \%$ & $0.000476 \%$ & $0.001095 \%$ & $0.004262 \%$ & EOM & 2 \\
\hline 5 & 131 & $3.66 \%$ & $0.001480 \%$ & $0.000162 \%$ & $0.000843 \%$ & $0.001443 \%$ & BOM & 3 \\
\hline 11 & 112 & $3.13 \%$ & $0.000776 \%$ & $0.000315 \%$ & $0.000610 \%$ & $0.001720 \%$ & Days near EOM but very similar to TYPICAL. & 1 \\
\hline 12 & 88 & $2.46 \%$ & $0.002465 \%$ & $0.001456 \%$ & $0.001498 \%$ & $0.006502 \%$ & BULL DAY, mostly after 2009. & 6 \\
\hline 15 & 45 & $1.26 \%$ & $0.009190 \%$ & $0.002392 \%$ & $-0.000087 \%$ & $0.000798 \%$ & $\begin{array}{l}\text { OVERBOUGHT: Significant positive returns at the } \\
\text { open but reverses during the day; high volatility, } \\
\text { liquidity; national currency appreciation; spillover } \\
\text { effects. }\end{array}$ & 5 \\
\hline 3 & 43 & $1.20 \%$ & $0.002142 \%$ & $0.002508 \%$ & $0.001193 \%$ & $0.005378 \%$ & BULL DAY, mostly around BOM before 2009. & 6 \\
\hline 8 & 42 & $1.17 \%$ & $-0.004797 \%$ & $-0.002431 \%$ & $0.000918 \%$ & $0.010118 \%$ & $\begin{array}{l}\text { OVERSOLD: Significant negative returns at the open } \\
\text { but reverses during the day; high volatility, liquidity; } \\
\text { national currency depreciation; spillover effects. }\end{array}$ & 4 \\
\hline 4 & 41 & $1.14 \%$ & $-0.006896 \%$ & $-0.004251 \%$ & $0.001795 \%$ & $0.006645 \%$ & $\begin{array}{l}\text { OVERSOLD: Significant negative returns at the open } \\
\text { but reverses during the day; high volatility, liquidity; } \\
\text { national currency depreciation; spillover effects. }\end{array}$ & 4 \\
\hline 17 & 8 & $0.22 \%$ & $-0.004975 \%$ & $0.001846 \%$ & $0.001628 \%$ & $0.004680 \%$ & $\begin{array}{l}\text { OVERSOLD: Significant negative returns at the open } \\
\text { but reverses during the day; high volatility, liquidity; } \\
\text { national currency depreciation; spillover effects. }\end{array}$ & 4 \\
\hline 14 & 1 & $0.03 \%$ & $-0.000380 \%$ & $0.000304 \%$ & $0.000651 \%$ & $-0.002038 \%$ & N./A & N/A \\
\hline
\end{tabular}

The second most predominant type of patterns are displayed in Panel C of Figure 3 and occur roughly $7.48 \%$ of the time. These are clearly related to calendar effects, specifically to the last day of the month (EOM) and to the first day of the month (BOM). Even though they both resemble the TYPICAL pattern in terms of overall shape, significant differences can be observed when looking at the distribution of intraday returns (e.g., skewness and kurtosis in the case of EOM) and the average returns associated to each effect. On the one hand, mid-day effects on EOM days are significantly higher compared to TYPICAL, while the CLOSE effect if almost 2 times larger. This points towards "window dressing" practices as a possible driver of intraday patterns. On the other hand, average returns on BOM days are generally lower, culminating in a CLOSE effect that is significantly lower than TYPICAL. This possibly implies a reversal effect on BOM days following EOM days, particularly an exhaustion of investor buying power towards the end of the BOM day, which causes the prices to rise less than usual.

The final group of three patterns, displayed in Panel D of Figure 3, occur in the remaining $7.45 \%$ of the time and seem to be related to information flows and investor behavior. First, the OVERSOLD pattern occurs on highly-volatile and highly-liquid trading days, both for the domestic and the two foreign markets. Also, intraday returns tend to be lower, return distributions are fat-tailed and negatively skewed, while the domestic exchange rate depreciates. This implies that systemically-important negative information is at the root of the pattern. When looking at the shape itself, we find that the OPEN and MID1 effects are significantly lower than usual but that the MID2 and CLOSE effects are 4 times higher than usual. This points towards investor overreaction to negative information, followed by a reversal effect, as the main explanation for the pattern, which occurs $2.54 \%$ of the time.

Second, the OVERBOUGHT pattern mirrors the OVERSOLD one, the difference being that it seems to occur in the presence of systemically-important positive information. In this case, the pattern is associated with high liquidity and volatility in both domestic and international markets, fat-tailed and positively-skewed return distributions, higher than usual foreign market returns, and an appreciation of the domestic currency. Returns in the first half of the day are significantly higher than usual but end up significantly lower than usual in the second part of the day. This again points towards investor overreaction (but now to positive information), followed by a reversal effect, as the main backdrop for the pattern. Interestingly, the OVERBOUGHT pattern occurs only $1.26 \%$ of the time, which is exactly 
2 times less frequent compared to the OVERSOLD pattern. This implies that an asymmetry exists between the occurrence of the two patterns, which echoes the findings in the behavioral finance literature regarding the asymmetric investor response to information (e.g., Hirshleifer, Huang, and Teoh, 2016).

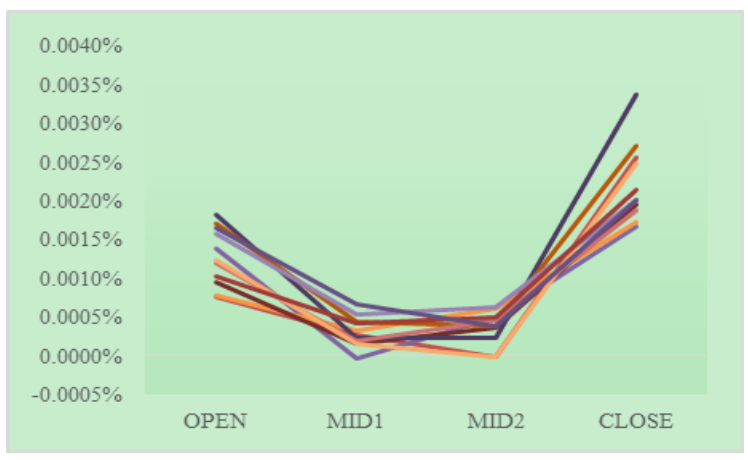

Panel A. 11 clusters of TYPICAL patterns

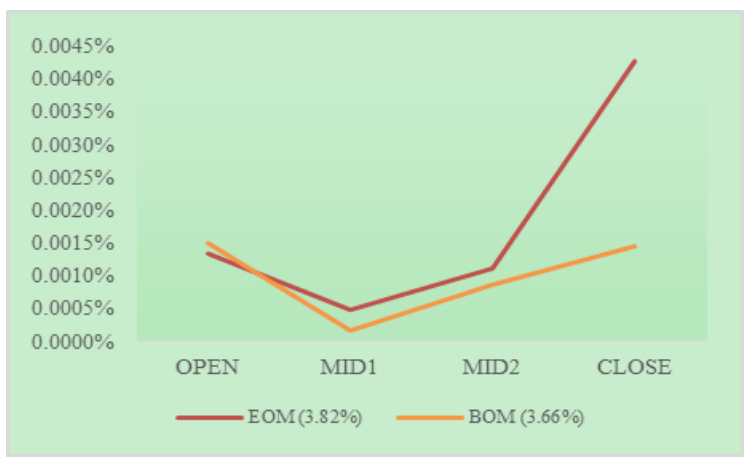

Panel C. Calendar-related patterns

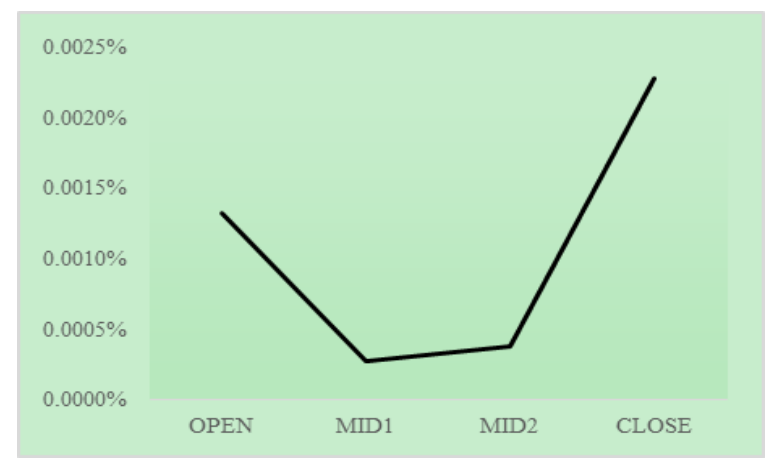

Panel B. Consolidated TYPICAL pattern

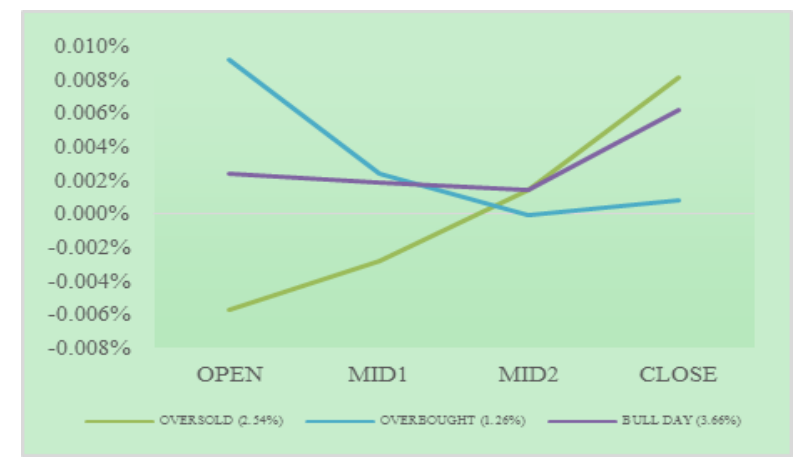

Panel D. Information-related patterns

Figure 3. Representative types of intraday patterns

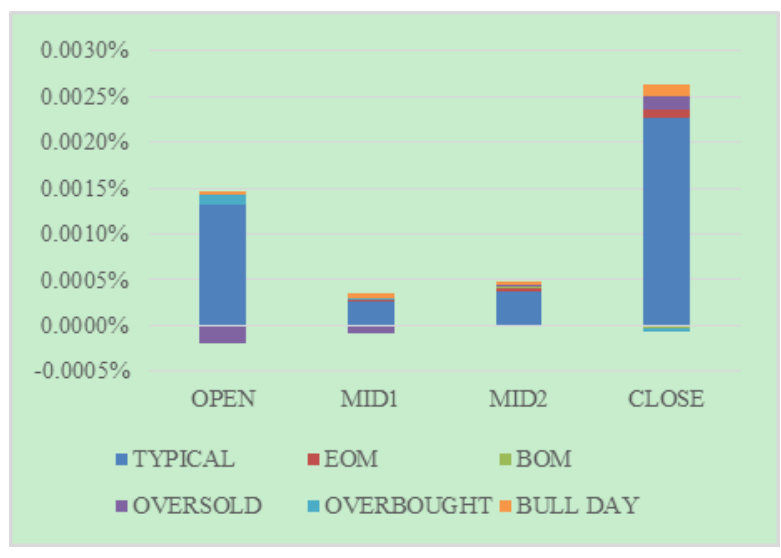

Panel A. Absolute value decomposition

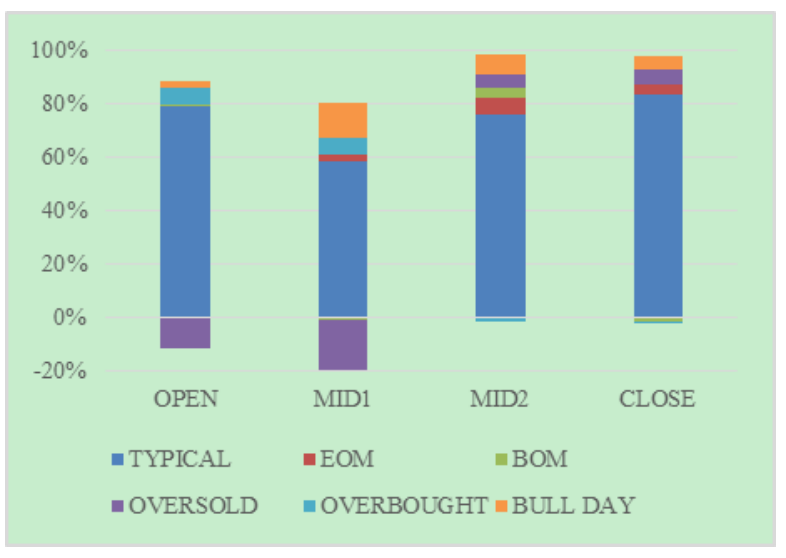

Panel B. Relative decomposition

Figure 4. Decomposition of intraday pattern in returns

Third, we observe a distinct BULL DAY pattern, when intraday returns are consistently higher than usual. Because, international markets do not seem to behave in an unusual way during such days, it seems that this is a reaction to locally-important positive information, which is incorporated into stock prices throughout the trading day. The 
difference between this and the previous two patterns seems to imply that the overreaction of local investors only occurs in the context of important foreign information and is related to information asymmetry, lower market efficiency, and spillover effects. We note however that the BULL DAY pattern is mainly related to shorter-than-average trading days, which implies that such days predominantly appear towards the start of our sample period, namely before the 2007-2009 financial crisis.

Finally, the clustering analysis enables us to perform a decomposition of the general intraday pattern based on the representative classes that have been identified. Figure 4 shows the results. We observe that the CLOSE and OPEN patterns are the most robust, while the MID1 is the least. Also, new market information and investor behavior explain much of the variation in intraday patterns, especially for the two effects that come early in the trading day. Conversely, the influence of calendar effects is less important and skewed towards the latter part of the day.

\section{Drivers of Intraday Patterns in Stock Returns}

The analysis in Section 3 additionally enables us to identify the variables that significantly correlate with the behavior of intraday patterns. By looking at the average standardized value associated with each variable and each cluster (Appendix B), we notice that patterns depend on domestic liquidity and volatility, changes in external market conditions (considering either SPX or DAX seems to be sufficient) and macroeconomic risk, as proxied by exchange rate movements. Further, specific calendar days and the duration of the trading session are important, while the different effects seem to correlate with each other (intraday auto-dependence in returns is present). In this section, we investigate the sensitivities of the different effects to these variables while accounting for the different types of patterns that we previously observed. In order to do this, we define and estimate the following linear model, which is based on the analysis in Section 3:

$$
E F F_{t}=\sum_{i=1}^{4}\left(D_{i, t}+D_{i, t} \sum_{j=1}^{14} X_{j, t}\right)+\varepsilon_{t}
$$

where EFF is one of the four intraday effects (OPEN, MID1, MID2, CLOSE), while the dummies $D_{i}$ and independent variables $X_{j}$ are listed in Table 3. Note that the first subset of 15 terms in the regression can be considered as modelling the responses of the different patterns to the independent variables in general, while the subsequent interaction terms can be considered as modelling changes in these responses that occur in the context of special market conditions, associated with the OVERBOUGHT, OVERSOLD, and BULL DAY patterns.

Table 3. List of variables: drivers of intraday patterns

\begin{tabular}{|c|c|c|}
\hline Variable & Associated coefficient & Description \\
\hline$D_{1}$ & $\mathrm{C}$ & Constant taking 1 on all days. \\
\hline$D_{2}$ & OVERBOUGHT & Takes 1 on days when the OVERBOUGHT pattern occurs and 0 otherwise. \\
\hline$D_{2}$ & OVERSOLD & Takes 1 on days when the OVERSOLD pattern occurs and 0 otherwise. \\
\hline$D_{4}$ & BULL_DAY & Takes 1 on days when the BULL_DAY pattern occurs and 0 otherwise. \\
\hline$X_{2}$ & EOMext & Takes 1 on for the last 5 trading days prior to EOM and 0 otherwise. \\
\hline$X_{z}$ & EOM & $\begin{array}{l}\text { Takes } 1 \text { on the final trading day of a calendar month and } 0 \text { otherwise. Proxy for the } \\
\text { end-of-the-month effect. }\end{array}$ \\
\hline$X_{x}$ & BOM & $\begin{array}{l}\text { Takes } 1 \text { on the first trading day of a calendar month and } 0 \text { otherwise. Proxy for the } \\
\text { beginning-of-the-month effect. }\end{array}$ \\
\hline$X_{4}$ & BOMext & Takes 1 on for the first 5 trading days after BOM and 0 otherwise. \\
\hline
\end{tabular}




\begin{tabular}{|c|c|c|}
\hline \multicolumn{2}{|c|}{ http://ijfr.sciedupress.com } & International Journal of Financial Research $\quad$ Vol. 11, No. 5; 2020 \\
\hline$Z_{s}$ & DAYLENGTH & Definition provided in Table 1. Proxy for the duration of the trading day. \\
\hline$X_{6}$ & EFF_PREVIOUS & $\begin{array}{l}\text { Value of previous effect. For CLOSE, the previous effect is MID2. For MID2, the previous effect } \\
\text { is MID1. For MID1, the previous effect is OPEN. For OPEN, the previous effect is ON. For ON, }\end{array}$ \\
\hline & & the previous effect is CLOSE recorded in the previous day. \\
\hline$X_{\mathbb{\tau}}$ & EFF_NOTRADES & Definition provided in Table 1 . Proxy for liquidity measured via trading frequency. \\
\hline$X_{\pi}$ & EFF_TURNOVER & Definition provided in Table 1. Proxy for liquidity measured via value of trades. \\
\hline$X_{*}$ & EFF_ATR & $\begin{array}{l}\text { Definition provided in Table } 1 \text {. Proxy for volatility. Depending on the intraday period, it correlates } \\
\text { significantly (between } 0.5643 \text { and } 0.6674 \text { ) with realized volatility (VOL). }\end{array}$ \\
\hline$X_{12}$ & EFF_CSSD & Definition provided in Table 1. Proxy for the cross-sectional dispersion of stock returns. \\
\hline$X_{12}$ & EURRON & Definition provided in Table 1. Proxy for changes in local macroeconomic conditions. \\
\hline$X_{2 z}$ & DAX_ONRET & $\begin{array}{l}\text { Definition provided in Table } 1 \text {. Proxy for overnight return in international financial markets. It has } \\
\text { a correlation of } 0.3053 \text { with SPX_INRET_1. }\end{array}$ \\
\hline$X_{2 x}$ & DAX_INRET & Definition provided in Table 1. Proxy for intraday return in international financial markets. \\
\hline$X_{24}$ & DAX_TR & Definition provided in Table 1. Proxy for intraday volatility in international financial markets. \\
\hline
\end{tabular}

Table 4 presents the results of estimating the model in Eq. (2). We would first note that, with the minor exception of MID2, the models fully explain the observed intraday patterns in returns, as can be inferred from the insignificant regression intercepts. Also, given the ample size of our data sample, the regressions explain a significant proportion of the variability in the intraday effects, as can be inferred from the R-squares ranging between 0.1465 and 0.2111. This latter result also shows that the OPEN and CLOSE effects are better explained by the model, as opposed to the two mid-day effects.

Table 4. Estimation results

\begin{tabular}{|c|c|c|c|c|}
\hline Dependent variable & EFF_OPEN & EFF_MID1 & EFF_MID2 & EFF_CLOSE \\
\hline \multirow[t]{2}{*}{$\mathrm{C}^{\perp}$} & 0.0620 & 0.0286 & -0.0660 & 0.0914 \\
\hline & {$[0.98]$} & {$[0.70]$} & {$[-1.74]^{*}$} & [1.34] \\
\hline \multirow[t]{2}{*}{ EOMext } & 0.0280 & 0.0048 & 0.0045 & 0.0177 \\
\hline & {$[1.20]$} & {$[0.33]$} & {$[0.35]$} & [0.78] \\
\hline \multirow[t]{2}{*}{ EOM } & 0.0223 & 0.0518 & 0.0433 & 0.1317 \\
\hline & {$[0.48]$} & {$[1.80]^{*}$} & {$[1.72]^{*}$} & {$[2.97]^{* * *}$} \\
\hline \multirow[t]{2}{*}{ BOM } & 0.0375 & 0.0015 & 0.0418 & -0.0329 \\
\hline & {$[0.77]$} & {$[0.04]$} & {$[1.57]$} & {$[-0.70]$} \\
\hline \multirow[t]{2}{*}{ BOMext } & 0.0370 & 0.0297 & 0.0034 & 0.0080 \\
\hline & {$[1.57]$} & {$[2.00]^{* *}$} & {$[0.26]$} & [0.35] \\
\hline \multirow[t]{2}{*}{ DAYLENGTH } & 0.0000 & 0.0000 & 0.0001 & 0.0000 \\
\hline & {$[-0.11]$} & {$[-0.01]$} & {$[2.29]^{* *}$} & {$[-0.73]$} \\
\hline \multirow[t]{2}{*}{ EFF_PREVIOUS } & 14.9671 & 371.4515 & 492.8204 & 474.6784 \\
\hline & {$[9.48]^{* * *}$} & {$[2.99] * * *$} & {$[2.74]^{* * *}$} & [1.37] \\
\hline EFF_NOTRADES & -0.9337 & -0.6372 & 0.2373 & -0.6020 \\
\hline
\end{tabular}




\begin{tabular}{|c|c|c|c|c|}
\hline & {$[-2.67] * * *$} & {$[-1.72]^{*}$} & {$[0.65]$} & {$[-1.65]^{*}$} \\
\hline \multirow[t]{2}{*}{ EFF_TURNOVER } & 0.0000 & 0.0000 & 0.0000 & 0.0000 \\
\hline & {$[-0.25]$} & {$[1.07]$} & {$[0.08]$} & {$[0.48]$} \\
\hline \multirow[t]{2}{*}{ EFF_ATR } & 809.7335 & 886.1762 & -1993.5486 & -534.1396 \\
\hline & {$[2.97]^{* * *}$} & {$[2.78]^{* * *}$} & {$[-5.49] * * *$} & {$[-1.56]$} \\
\hline \multirow[t]{2}{*}{ EFF_CSSD } & 408.2718 & -76.3372 & 647.7267 & 683.8444 \\
\hline & {$[7.35]^{* * *}$} & {$[-1.36]$} & {$[11.32]^{* * *}$} & {$[17.27]^{* * *}$} \\
\hline \multirow[t]{2}{*}{ EURRON } & -7.6131 & -7.2973 & -2.4759 & -0.5153 \\
\hline & {$[-2.41] * *$} & {$[-3.68]^{* * *}$} & {$[-1.43]$} & {$[-0.17]$} \\
\hline \multirow[t]{2}{*}{ DAX_ONRET } & 11.7749 & 2.7021 & 0.3342 & -2.2719 \\
\hline & {$[6.77]^{* * *}$} & {$[2.48]^{* *}$} & {$[0.35]$} & {$[-1.38]$} \\
\hline \multirow[t]{2}{*}{ DAX_INRET } & 1.4935 & 2.9490 & 2.5583 & 2.4591 \\
\hline & {$[1.65]^{*}$} & {$[5.20]^{* * *}$} & {$[5.15]^{* * *}$} & {$[2.82]^{* * *}$} \\
\hline \multirow[t]{2}{*}{ DAX_TR } & -0.7197 & -1.0452 & -1.9747 & -2.2668 \\
\hline & {$[-0.65]$} & {$[-1.50]$} & {$[-3.29]^{* * *}$} & {$[-2.16]^{* *}$} \\
\hline \multirow[t]{2}{*}{ OVERBOUGHT } & -0.5277 & -1.6218 & -0.8078 & -0.3894 \\
\hline & {$[-0.67]$} & {$[-2.80] * * *$} & {$[-1.76]^{*}$} & {$[-0.31]$} \\
\hline \multirow[t]{2}{*}{ OVERBOUGHT×EOMext } & 1.0552 & -0.6714 & 0.2386 & 0.9167 \\
\hline & {$[3.43]^{* * *}$} & {$[-3.31] * * *$} & {$[1.53]$} & {$[3.37]^{* * *}$} \\
\hline \multirow[t]{2}{*}{ OVERBOUGHT×EOM } & 1.1862 & -0.3903 & 0.5988 & 0.7722 \\
\hline & {$[3.22]^{* * *}$} & {$[-1.72]^{*}$} & {$[3.28]^{* * *}$} & {$[2.18]^{* *}$} \\
\hline \multirow[t]{2}{*}{ OVERBOUGHT×BOM } & 2.3853 & -0.7117 & 1.2776 & 1.4746 \\
\hline & {$[3.69]^{* * *}$} & {$[-1.78]^{*}$} & {$[3.94]^{* * *}$} & {$[2.23]^{* *}$} \\
\hline \multirow[t]{2}{*}{ OVERBOUGHT×BOMext } & 1.4832 & -0.0540 & 0.3002 & 0.7013 \\
\hline & {$[4.86]^{* * *}$} & {$[-0.30]$} & {$[2.02]^{* *}$} & {$[2.52]^{* *}$} \\
\hline \multirow[t]{2}{*}{ OVERBOUGHT $\times$ DAYLENGTH } & -0.0089 & 0.0068 & 0.0000 & -0.0006 \\
\hline & {$[-4.32]^{* * *}$} & {$[4.86]^{* * *}$} & {$[-0.07]$} & {$[-0.23]$} \\
\hline \multirow[t]{2}{*}{ OVERBOUGHT×EFF_PREVIOUS } & 1.6379 & 105.5402 & -53.1124 & 242.3948 \\
\hline & {$[0.18]$} & {$[0.25]$} & {$[-0.08]$} & [0.14] \\
\hline \multirow[t]{2}{*}{ OVERBOUGHT×EFF_NOTRADES } & 15.2100 & -5.6415 & 2.7698 & 2.4693 \\
\hline & {$[4.94]^{* * *}$} & {$[-2.03]^{* *}$} & {$[1.30]$} & {$[0.43]$} \\
\hline \multirow[t]{2}{*}{ OVERBOUGHT×EFF_TURNOVER } & -0.0002 & 0.0005 & 0.0000 & 0.0001 \\
\hline & {$[-2.60] * * *$} & {$[5.20]^{* * *}$} & {$[0.39]$} & [1.21] \\
\hline \multirow[t]{2}{*}{ OVERBOUGHT $\times$ EFF_ATR } & -1558.9596 & -2346.5355 & 1198.3677 & -75.3405 \\
\hline & {$[-1.62]$} & {$[-2.64] * * *$} & [1.16] & {$[-0.02]$} \\
\hline \multirow[t]{2}{*}{ OVERBOUGHT×EFF_CSSD } & -136.7497 & 1699.5260 & -422.7467 & -1624.5096 \\
\hline & {$[-0.46]$} & {$[6.34]^{* * *}$} & {$[-1.56]$} & {$[-6.30]^{* * *}$} \\
\hline \multirow[t]{2}{*}{ OVERBOUGHT $\times$ EURRON } & -11.9323 & 20.1229 & -20.6752 & -54.6239 \\
\hline & {$[-0.76]$} & {$[2.11]^{* *}$} & {$[-2.27]^{* *}$} & {$[-3.71]^{* * *}$} \\
\hline \multirow[t]{2}{*}{ OVERBOUGHT×DAX_ONRET } & 11.0568 & -8.3401 & 32.2353 & 15.3501 \\
\hline & [1.43] & {$[-1.64]^{*}$} & {$[8.02]^{* * *}$} & {$[1.67]^{*}$} \\
\hline \multirow[t]{2}{*}{ OVERBOUGHT×DAX_INRET } & 17.3528 & 2.0784 & 12.3525 & 14.7962 \\
\hline & {$[4.40]^{* * *}$} & {$[0.88]$} & {$[6.24]^{* * *}$} & {$[3.53]^{* * *}$} \\
\hline \multirow[t]{2}{*}{ OVERBOUGHT×DAX_TR } & 20.2850 & -14.9793 & 2.4055 & 9.0359 \\
\hline & {$[4.23]^{* * *}$} & {$[-4.52]^{* * *}$} & {$[0.90]$} & {$[2.02]^{* *}$} \\
\hline OVERSOLD & 1.3258 & 0.5198 & -0.8829 & 1.0702 \\
\hline & {$[4.26]^{* * *}$} & {$[2.13]^{* *}$} & {$[-3.45] * * *$} & {$[2.17]^{* *}$} \\
\hline OVERSOLD×EOMext & -0.4340 & 0.0078 & 0.0346 & -0.2733 \\
\hline & {$[-2.74] * * *$} & {$[0.07]$} & {$[0.39]$} & {$[-1.77]^{*}$} \\
\hline OVERSOLD×EOM & -0.1201 & 0.5098 & 0.2434 & 1.2502 \\
\hline
\end{tabular}




\section{OVERSOLD $\times B O M$ \\ OVERSOLD×BOMext \\ OVERSOLD $\times$ DAYLENGTH

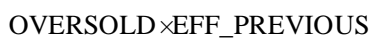 \\ OVERSOLD×EFF_NOTRADES \\ OVERSOLD $\times E F F \_T U R N O V E R$ \\ OVERSOLD×EFF_ATR \\ OVERSOLD $\times E F F \_C S S D$ \\ OVERSOLD×EURRON \\ OVERSOLD $\times D A X \_O N R E T$ \\ OVERSOLD×DAX_INRET \\ OVERSOLD $\times D A X \_T R$}

BULL_DAY

BULL_DAY×EOMext

BULL_DAY×EOM

BULL_DAY $\times$ BOM

BULL_DAY $\times$ BOMext

BULL_DAY $\times$ DAYLENGTH

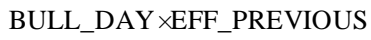

BULL_DAY $\times$ EFF_NOTRADES

BULL_DAY $\times E F F \_T U R N O V E R$

BULL_DAY $\times$ EFF_ATR

BULL_DAY $\times$ EFF_CSSD

BULL_DAY×EURRON

BULL_DAY $\times$ DAX_ONRET

$$
\text { [-0.55] }
$$

0.1942

[0.33]

$-0.2444$

[-1.58]

$-0.0021$

$[-2.48]^{* *}$

$-34.5377$

$[-7.25]^{* * *}$

0.7796

[0.95]

0.0000

[0.20]

$-4321.5535$

$[-7.76]^{* * *}$

$-670.5492$

$[-6.35]^{* * *}$

1.8803

[0.18]

2.2419

[0.41]

1.5081

[0.52]

2.3464

[0.72]

$-1.1460$

$[-2.58]^{* * *}$

0.7903

[3.04]***

0.6770

$[2.07]^{* *}$

0.1238

[0.20]

0.7098

[2.82]***

0.0019

[1.65]*

41.5134

[4.63]***

$-1.3387$

[-0.79]

0.0000

[-0.38]

1333.1448

[1.31]

1259.8539

[7.55]***

$-11.3814$

[-0.71]

14.6859

[1.10]

$$
\begin{array}{r}
{[3.80]^{* * *}} \\
-0.5508 \\
{[-1.55]} \\
0.0940 \\
{[0.98]} \\
-0.0007 \\
{[-1.57]} \\
-391.1693 \\
{[-1.48]} \\
2.6857 \\
{[1.68] *} \\
0.0000
\end{array}
$$

[-1.55]

0.0940

[0.98]

$-0.0007$

2.6857

[1.68]*

[1.78]*

$-8746.8397$

[-9.68] $]^{* * *}$

652.9082

[4.82] $]^{* * *}$

8.2704

[1.28]

$-14.3051$

[-4.86]***

5.1888

[2.93]***

$-2.9440$

[-1.47]

$-0.5628$

[-1.72]*

$-0.0088$

[-0.05]

$-0.3670$

[-1.79]*

0.7277

[1.94]*

$-0.0714$

[-0.44]

0.0002

[0.40]

495.7454

[1.02]

$-0.7867$

[-0.38]

0.0000

[-0.51]

6059.9308

[5.34]***

380.2615

[1.31]

9.0787

[0.89]

31.1748

[4.04]***

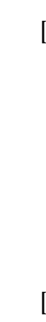

[-0.62] 


\begin{tabular}{|c|c|c|c|c|}
\hline BULL_DAY $\times$ DAX_INRET & $\begin{array}{r}-3.4440 \\
{[-0.58]}\end{array}$ & $\begin{array}{r}-4.3665 \\
{[-1.18]}\end{array}$ & $\begin{array}{r}0.1209 \\
{[0.03]}\end{array}$ & $\begin{array}{r}19.8998 \\
{[3.40]^{* * * *}}\end{array}$ \\
\hline BULL_DAY $\times$ DAX_TR & $\begin{array}{l}-16.9239 \\
{[-2.25]^{* *}} \\
\end{array}$ & $\begin{array}{r}-1.0091 \\
{[-0.21]} \\
\end{array}$ & $\begin{array}{r}-14.4183 \\
{[-3.57]^{* * *}} \\
\end{array}$ & $\begin{array}{l}-15.8912 \\
{[-2.23]^{* *}}\end{array}$ \\
\hline No. Observations & 3582 & 3582 & 3582 & 3582 \\
\hline Adjusted R-squared & 0.2111 & 0.1596 & 0.1465 & 0.1909 \\
\hline F-statistic & $17.25 * * *$ & $12.53 * * *$ & $11.41 * * *$ & $15.32 * * *$ \\
\hline Akaike info criterion & -7.63 & -8.55 & -8.83 & -7.70 \\
\hline Schwarz criterion & -7.53 & -8.45 & -8.72 & -7.60 \\
\hline Hannan-Quinn criterion & -7.59 & -8.51 & -8.79 & -7.66 \\
\hline Durbin-Watson statistic & 1.96 & 1.85 & 1.99 & 1.92 \\
\hline Jarque-Bera statistic & & & & \\
\hline
\end{tabular}

Note. t-statistics are reported in squared parenthesis. ***,**, and $*$ denote statistical significance at the $1 \%, 5 \%$, and $10 \%$ levels, respectively. $\perp$ To obtain demeaned average returns for each effect from the regression intercepts, one can subtract the average return in the entire sample, which is 0.000542 per 1 minute.

When analyzing the (first 15) estimated coefficients, several interesting findings are worth noting about the general drivers of intraday patterns. First, all 4 intraday effects are positively related to intraday returns on the DAX index. In addition, the OPEN and MID1 effects also respond to DAX overnight returns, while the MID2 and CLOSE effects respond to DAX intraday volatility. This shows that foreign information flows and spillover effects from more developed markets are one of the main drivers of intraday patterns in stock returns on the Romanian market. Similarly, the OPEN and MID1 effects are significantly related to domestic currency appreciation, showing that local information on the state of the economy is also important.

Second, a rise in intraday volatility or the cross-sectional dispersion of stock returns is generally associated with a significant increase in intraday returns throughout the day. This shows that market risk is an important determinant of intraday patterns, as higher risk increases the returns associated to each effect. As an exception to this, the MID2 effect negatively relates to ATR, while the response of CLOSE is also negative but not statistically significant. This signals that risk is asymmetrically priced in the first part of the day and also that it may be overpriced, with a reversal effect occurring in the second part of the day.

Third, we find significant evidence of the gradual diffusion of information into stock prices. On the one hand, the coefficients on EFF_PREVIOUS are strongly positive and statistical significant for the first 3 effects on the day. On the other hand, as discussed earlier, the information arriving from foreign markets seems to be incorporated throughout the day, not only at the start. Both results imply that lower market efficiency, which is a characteristic of frontier stock markets (see, e.g., Anghel, 2017, for a specific discussion on Romania), is a significant determinant of intraday patterns in stock returns.

Fourth, as opposed to turnover, trading frequency has a significant influence on intraday returns. Surprisingly, all the statistically significant coefficients on NOTRADES are negative, pointing towards liquidity as a negative determinant of the returns associated with the different patterns. This result may be explained by relating it to the behavioral finance literature. Specifically, because liquidity can be associated with higher informational efficiency and a lower influence of noise/uninformed traders (e.g., Chordia, Roll, and Subrahmanyam, 2008), it may signal that some of the significant positive returns associated with the various intraday patterns come as a result of investor "irrational exuberance" (e.g., Phillips, Wu, and Yu, 2011) that is occasionally corrected by the actions of informed traders, with the presence of the latter being signaled by increased trading frequency. However, while this explanation is possible, especially for a less developed and less efficient stock market such as Romania (Anghel, 2017), additional research is needed to more directly investigate this topic and explain this result.

Fifth, we find significantly higher intraday effects in the last day of calendar months (EOM), which progressively get stronger towards the market closing time. Interestingly, and contrary to earlier observations, a reversal of this effect does not seem to occur on the next trading day. Instead, we mostly find positive returns in BOM and BOMext days but these are not generally statistical significant. Overall, the results imply that an "end of the month" effect is influencing intraday patterns. Even though more direct evidence might be needed to state a definite conclusion, we feel that this effect is most likely explained by "making the close", "window dressing" practices by large, 
institutional investors; especially because similar evidence exists on larger and more liquid stock markets (see, Putninšs, 2012, for a review of the related literature).

Sixth, we find that DAYLENGTH has a significant influence on MID2, while it does not generally affect the other intraday effects. Because the trading program in the Romanian market has increased to specifically overlap with more developed European markets and also to cover the market open of the US market (NYSE opens at 4:30 PM local time), this result seems to indicate the effect of surplus foreign information on local stock prices during longer trading days.

Besides these general determinants of patterns in intraday stock returns, we find additional evidence to show that low market efficiency and investor overreaction to information are significantly determining intraday prices in the specific cases of days presenting OVERBOUGHT, OVERSOLD, or BULL DAY patterns. For example, the average return associated with the OPEN effect in OVERBOUGHT days significantly increases with DAX return and volatility, which signals an overreaction to important foreign information. Also, the OPEN effect increases on EOMext, EOM, BOM, and BOMext days, which signals more positive investor sentiment around the turn of the calendar month. However, the same coefficients (plus the OVERBOUGHT dummy) are negative and statistically significant when the MID1 effect is considered, showing that the initial overreaction quickly reverses. Interestingly, the OPEN effect reacts positively to the number of trades and negatively to turnover. This implies that the price rises are cause by a significant increase in the frequency of small buy orders, which constitutes evidence of small, probably uninformed traders overreacting to the market information. This trend in liquidity is also reversed in the MID2 period, signaling that large, informed investors are entering the scene. These patterns in returns and liquidity again reverse in the MID2 and CLOSE periods, showing that the balance between the different categories of investors is rather thin during such days. Also, we observe a similar asymmetric behavior of the effect of macroeconomic news (the exchange rate) between the first part and the second part of the day.

OVERSOLD days are similar to OVERBOUGHT days in pointing towards investor overreaction. However, they seem to relate more to news, mostly on the local market (the volatility and cross-sectional dispersion of returns have significantly more predictive power over all effects) and less to calendar effects. Also, the reversals can be directly observed in the predominately negative and statistically significant coefficients associated with the EFF_PREVIOUS interaction term. Further, the previous observed influence (and reversal) of the two liquidity variables are observed in the second part of the OVERSOLD day, as opposed to the first part of the OVERBOUGHT day. Finally, we find that the DAYLENGTH interaction term is generally significant and shows that the effects of the various drivers are stronger when trading days are shorter.

Overall, our results show that the drivers of intraday returns are diverse, giving rise to several distinct patterns. On the one hand, information flows and spillover effects from more developed international markets seem to play the most important and consistent role. This is somewhat expected for a small, frontier stock markets such as that in Romania. On the other hand, we find that low informational efficiency and several types of investor behavior can significantly alter these patterns in specific circumstances. The length of the trading day is yet another source of difference, showing that small, less developed stock market do behave differently from their larger, more developed international counterparts.

\section{Conclusions}

This paper investigates the drivers of intraday patterns in returns on the frontier stock market of Romania, using a combination of clustering models estimated via Machine Learning and classical linear regression models. Our findings provide several interesting contributions to the related literature. First, we find that intraday patterns do not take a single form but instead come in several shapes that can appear in relation to specific market events or calendar dates. Our analysis shows that a general, TYPICAL, pattern occurs in the market roughly $85 \%$ of the time, this mostly originating from three sources: (1) domestic information flows and the overnight accumulation of information (this mainly impacts returns in the first part of the day), (2) spillover effects from important international markets, which may be associated with information asymmetry and relatively lower market efficiency, and (3) inventory risk related to the holding of overnight positions (this mainly impacts returns around the market closing time).

The remaining $15 \%$ of the time is equally split between calendar-related patterns and important information-related patterns. On the one hand, the calendar-related patterns arise around the turn of the month and most probably originate in "making the close", "window dressing" practices by institutional investors (Comerton-Forde and Putniņš, 2011). On the other hand, the information-related patterns seem the most intriguing: we find evidence that they arise in the context of small, uninformed traders overreacting to overnight information, this being followed by a reversal effect that can be most probably associated to the intervention of larger, informed investors. Moreover, we find that 
overreaction to negative information appears twice as frequent compared to the overreaction to positive information, showing that the asymmetric effects of information that are well documented in the literature (e.g., Hirshleifer et al., 2016) also plays a role in shaping intraday patterns.

The current analysis does present some limitations that can be addressed in future research. First, only one market is considered but the analysis would greatly benefit from expanding the data sample on other markets, either emerging or developed. Second, we only provide indirect evidence for the impact of behavioral factors such as overreaction to information or "making the close" practices, even though more direct evidence would be preferred. Third, we only investigate the drivers of intraday patterns within a linear framework, although non-linear relationships may also exist. Finally, we only consider a static specification, while the introduction of a dynamic component might improve the explanation power of the model.

Nevertheless, our paper confirms that some drivers that were previously identified in the literature are also responsible for shaping intraday patterns in the frontier stock market of Romania. In addition, the specific characteristics of the market that we investigate enable us to show that other factors exist, such as the length of the trading day, lower market efficiency, and spillover effects from more developed international markets. Most importantly, our paper shows that this diverse set of drivers give rise to an equally diverse group of distinct intraday patterns in stock returns. The use of Machine Learning clustering methods significantly contributes to this discovery, showing that Machine Learning is very well equipped to tackle various important topics in the financial economics literature. Among others, future research would benefit from considering clustering methods for analyzing intraday patterns in other, more developed stock markets, or even in financial markets such as foreign exchanges and cryptocurrencies.

\section{References}

Admati, A. R., \& Pfleiderer, P. (1989). Divide and conquer: A theory of intraday and day-of-the-week mean effects. The Review of Financial Studies, 2(2), 189-223.

Ahn, H. J., \& Cheung, Y. L. (1999). The intraday patterns of the spread and depth in a market without market makers: The stock exchange of Hong Kong. Pacific-Basin Finance Journal, 7, 539-556.

Amihud, Y., \& Mendelson, H. (1987). Trading mechanisms and stock returns: An empirical investigation. The Journal of Finance, 42(3), 533-553.

Andersen, T. G., Bollerslev, T., \& Cai, J. (2000). Intraday and interday volatility in the Japanese stock market. Journal of International Financial Markets, Institutions and Money, 10, 107-130.

Anghel, D. G. (2017). Intraday Market Efficiency for a Typical Central and Eastern European Stock Market: The Case of Romania. Romanian Journal of Economic Forecasting, 20(3), 88.

Anghel, D. G., Țilică, E., \& Dragotă, V. (2020). Intraday Patterns in Returns on Frontier Stock Markets, Romanian Journal of Economic Forecasting, 23(2).

Bildik, R. (2001). Intra-day seasonalities on stock returns: evidence from the Turkish Stock Market. Emerging Markets Review, 2(4), 387-417.

Block, S. B., French, D. W., \& Maberly, E. D. (2000). The pattern of intraday portfolio management decisions: A case study of intraday security return patterns. Journal of Business Research, 50(3), 321-326.

Breedon, F., \& Ranaldo, A. (2013). Intraday patterns in FX returns and order flow. Journal of Money, Credit and Banking, 45(5), 953-965.

Chordia, T., Roll, R., \& Subrahmanyam, A. (2008). Liquidity and market efficiency. Journal of Financial Economics, 87(2), 249-268.

Comerton-Forde, C., \& Putninšs, T. J. (2011). Measuring closing price manipulation. Journal of Financial Intermediation, 20(2), 135-158.

Fama, E. F. (1970). Efficient capital markets: A review of theory and empirical work. The Journal of Finance, 25(2), 383-417.

Gao, L., Han, Y., Li, S. Z., \& Zhou, G. (2018). Market intraday momentum. Journal of Financial Economics, 129(2), 394-414.

Géron, A. (2019). Hands-On Machine Learning with Scikit-Learn, Keras, and TensorFlow: Concepts, Tools, and Techniques to Build Intelligent Systems. O'Reilly Media. 
Hirshleifer, D. A., Huang, C., \& Teoh, S. H. (2016, April). Information Asymmetry, Market Participation, and Asset Prices. In 6th Miami Behavioral Finance Conference.

Marin, J. M., Mengersen, K., \& Robert, C. P. (2005). Bayesian modelling and inference on mixtures of distributions. Handbook of Statistics, 25, 459-507.

Phillips, P. C., Wu, Y., \& Yu, J. (2011). Explosive behavior in the 1990s Nasdaq: When did exuberance escalate asset values?. International Economic Review, 52(1), 201-226.

Putninšs, T. J. (2012). Market manipulation: A survey. Journal of Economic Surveys, 26(5), 952-967.

Renault, T. (2017). Intraday online investor sentiment and return patterns in the US stock market. Journal of Banking \& Finance, 84, 25-40.

Tissaoui, K. (2012). The intraday pattern of trading activity, return volatility and liquidity: Evidence from the emerging Tunisian stock exchange. International Journal of Economics and Finance, 4(5), 156-176.

Vo, M. T. (2007). Limit orders and the intraday behavior of market liquidity: Evidence from the Toronto stock exchange. Global Finance Journal, 17, 379-396.

Wood, R. A., McInish, T. H., \& Ord, J. K. (1985). An investigation of transactions data for NYSE stocks. The Journal of Finance, 40(3), 723-739.

Yadav, P. K., \& Pope, P. F. (1992). Intraweek and intraday seasonalities in stock market risk premia: Cash and futures. Journal of Banking \& Finance, 16(1), 233-270.

Zhang, H. (2018). Intraday patterns in foreign exchange returns and realized volatility. Finance Research Letters, 27, 99-104.

\section{Notes}

Note 1. For the period from December 12, 2015 to June 14, 2016 we do not find the necessary data, which leaves a gap in our sample.

Note 2. We consider the return is zero when observations are missing, i.e. in minutes when no trades have been performed.

Note 3. Both the MID1 and MID2 effects can be extended in long trading days a further 30-60 minutes (Anghel et al., 2020) or even towards the middle of the day. Here, we only use 90 minutes because they are representative for the price action in the extended interval and also for consistency, because the shortest trading days in our sample only have a total of 240 minutes (4 hours).

Note 4. Note that we loosely use OPEN, MID, MID2, and CLOSE throughout the paper, denoting either the effect itself, the time interval in which it occurs, or the average return associated with it, depending on the context.

Note 5. Géron (2019) provides additional information on the implementation. An overview of the model hyperparameters is provided by https://scikit-learn.org/stable/modules/generated/sklearn.mixture.BayesianGaussianMixture.html [accessed June 9, 2020].

\section{Copyrights}

Copyright for this article is retained by the author(s), with first publication rights granted to the journal.

This is an open-access article distributed under the terms and conditions of the Creative Commons Attribution license (http://creativecommons.org/licenses/by/4.0/). 